\title{
Cryptogenic Organizing Pneumonia Mimicking Malignancy in a Patient with Rheumatoid Arthritis
}

MARIA KONSTA, MD; VASSILIKI-KALLIOPI BOURNIA, MD, Veterans Administration Hospital (NIMTS), 10-12 Monis Petraki Str, Athens, 11521, Greece; PARASKEVI ALEXANDROU, MD, Department of Pathology, Medical School, University of Athens; ALEXIOS ILIOPOULOS, MD, Veterans Administration Hospital, Athens, Greece. Address correspondence to Dr. Konsta; E-mail:markonsta@ hotmail.com. J Rheumatol 2011;38:2007-8; doi: $10.3899 /$ jrheum.110282

A 53-year-old woman with an 8-year history of rheumatoid arthritis (RA) presented with fatigue and malaise. She had no evidence of tender or swollen joints. Laboratory investigations revealed anemia (hemoglobin $10.2 \mathrm{~g} / \mathrm{dl}$ ) of recent onset and an unexpectedly elevated erythrocyte sedimentation rate (114 $\mathrm{mm} / \mathrm{h}$ ). A chest radiograph showed a well defined noncalcified solitary mass in the right lung (Figure 1). High-resolution computed tomography (CT) of the lungs revealed a spiculated lung in the upper right lobe, with a diameter of about $4 \mathrm{~cm}$ (Figure 2). The patient was a smoker (half-pack daily for 20 years) and in view of these findings open lung biopsy was performed to rule out malignancy. The biopsy showed histological features compatible with cryptogenic organizing pneumonia (COP; Figure 3). The patient was started on oral methylprednisolone $0.75 \mathrm{mg} / \mathrm{kg} / \mathrm{day}$, with great improvement of symptoms and radiologic and laboratory findings in the following month.

A patient with RA and a focal pulmonary opacity represents a difficult diagnostic dilemma, especially when confounded by a history of smoking and immunosuppression ${ }^{1}$. The presentation of COP as a solitary focal lesion is rare $^{2}$, requiring lung biopsy to establish the diagnosis and to exclude the possibility of malignancy ${ }^{3}$.

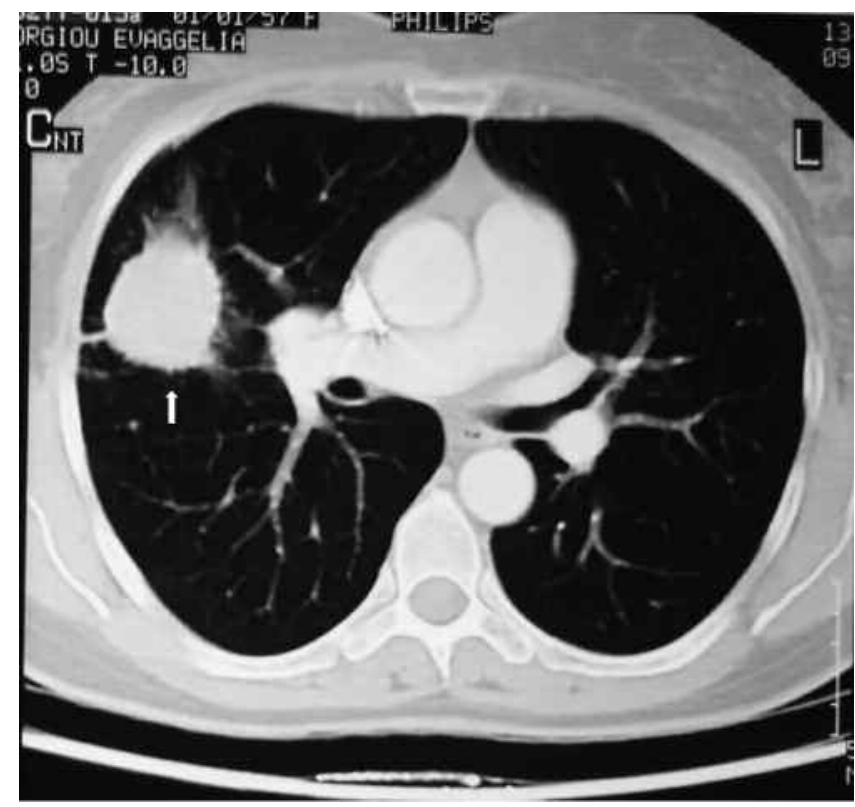

Figure 2. CT of the lung showing a round homogeneous mass with irregular border in the right upper lobe.

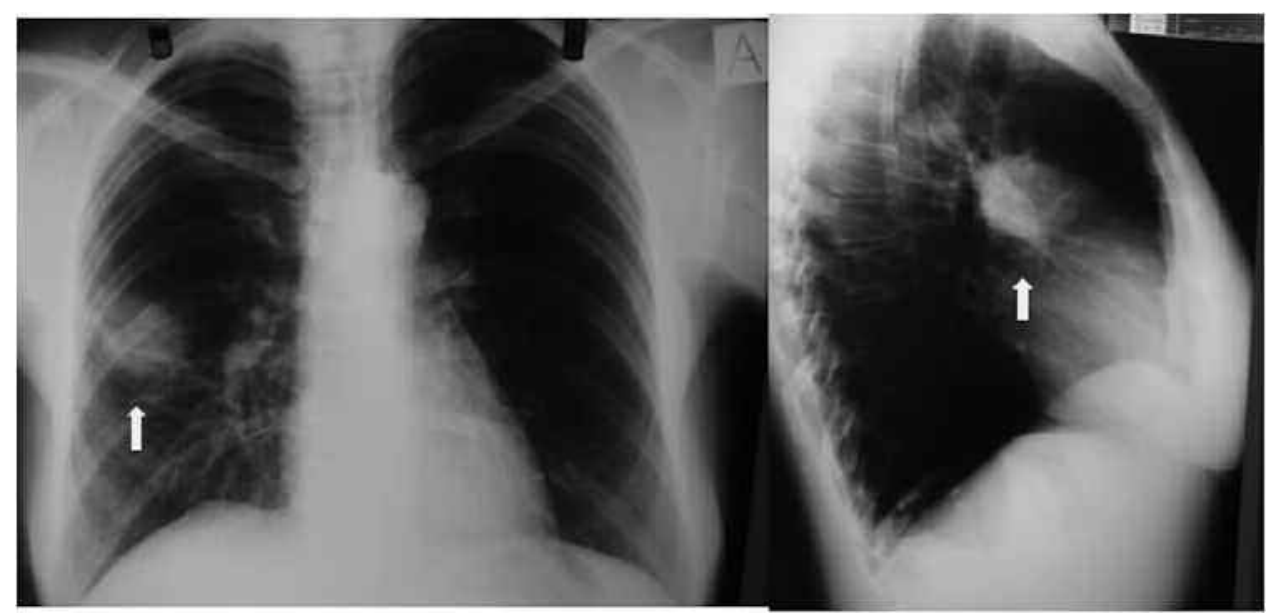

Figure 1. Chest radiograph showing a mass in the right lung. 


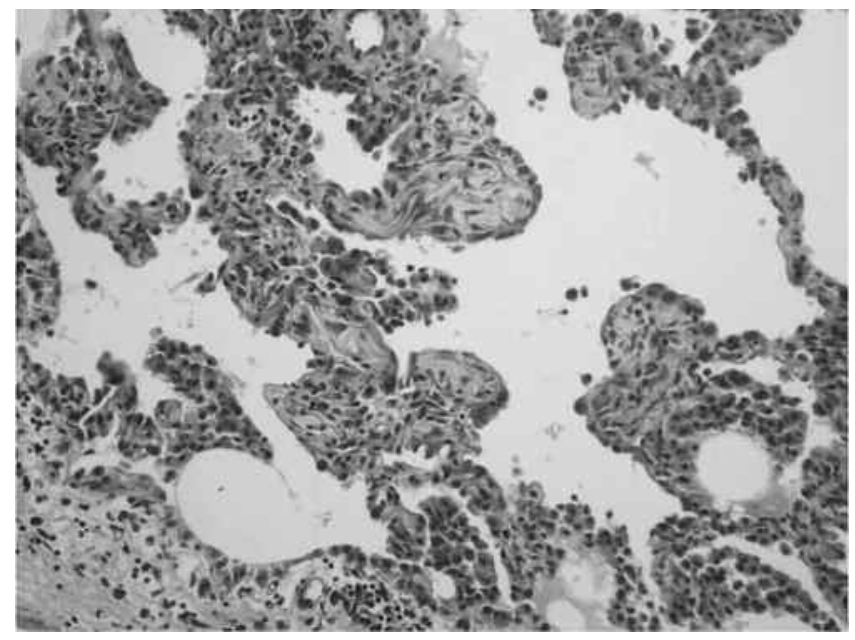

Figure 3. Open lung biopsy specimen showing fibroblastic proliferation plugs within alveolar spaces ("COP pattern"); H\&E stain, original magnification $\times 200$.

\section{REFERENCES}

1. Voulgari PV, Tsifetaki N, Metafratzi ZM, Zioga A, Acritidis NC, Drosos AA. A single pulmonary rheumatoid nodule masquerading as malignancy. Clin Rheumatol 2005;24:556-9.

2. Cordier JF. Organizing pneumonia. Thorax 2000;55:318-28.

3. Gould MK, Fletcher J, Iannettoni MD, Lynch WR, Midthun DE, Naidich DP, et al; American College of Chest Physicians. Evaluation of patients with pulmonary nodules: when is it lung cancer? ACCP evidence-based clinical practice guidelines (2nd edition). Chest 2007;132 Suppl 3:108-30. 